\title{
THE EFFECT OF MULTIPLANAR LOADING ON THE INTRADISCAL PRESSURE OF THE WHOLE HUMAN SPINE: A SYSTEMATIC REVIEW AND META-ANALYSIS
}

\author{
C. Liebsch and H.J. Wilke* \\ Institute of Orthopaedic Research and Biomechanics, Trauma Research Centre Ulm, Ulm University, \\ Ulm, Germany
}

\begin{abstract}
For spinal load and muscle force estimation as well as for numerical model and experimental setup validation, data on human intradiscal pressure are essential. Therefore, the aim of the present meta-analysis was to summarise all in vitro measurements of human intradiscal pressure performed under defined boundary conditions, i.e. without external loading (intrinsic pressure), under axial loading (compression, traction, shear) and under single-planar bending loading (flexion, extension, lateral bending, axial rotation). Data were evaluated based on segmental level and normalised to force and moment. Regression analysis was performed to investigate coefficients of determination and statistical significance of relationships between intradiscal pressure and segmental level for the single loading conditions. 35 studies fulfilled the inclusion criteria, from which a total of 451 data points were collected for the meta-analysis. High coefficients of determination were found in axial compression $\left(r^{2}=0.875\right)$ and flexion $\left(r^{2}=0.781\right)$, while being low for intrinsic pressure $\left(r^{2}=0.266\right)$ and lateral bending $\left(r^{2}=0.385\right)$, all showing significant regression fitting $(p<0.01)$. Intradiscal pressure decreases from the upper cervical spine to the sacrum in all loading conditions, considering the same amount of loading for all segmental levels, while the intrinsic pressure exhibits a minimum of the regression curve in the mid-thoracic spine. Apart from its potential for numerical and experimental model validation, this dataset may help to understand the load distribution along the human spine.
\end{abstract}

Keywords: Intradiscal pressure, human spine, meta-analysis, systematic review, multiplanar loading, model validation, biomechanics.

*Address for correspondence: Institute of Orthopaedic Research and Biomechanics, Helmholtzstraße 14, $89081 \mathrm{Ulm}$, Germany.

Telephone number: +49 73150055320 Email: hans-joachim.wilke@uni-ulm.de

Copyright policy: This article is distributed in accordance with Creative Commons Attribution Licence (http://creativecommons.org/licenses/by-sa/4.0/).

\section{Introduction}

Measurements of the pressure inside the intervertebral disc are essential for the estimation of loads and muscle forces on the spine as well as for the validation of numerical models and experimental setups in spine research. Moreover, variation in the intradiscal pressure represents an important indicator for pathologies such as intervertebral disc degeneration or spinal deformities. Since Nachemson first showed feasibility of intradiscal pressure measurements under in vitro loading conditions (Nachemson, 1959), numerous in vitro, in vivo and in silico studies have investigated the effects of body postures, external loads, ergonomics, surgical releases or spinal implants on the hydrostatic pressure inside the nucleus pulposus. However, due to the large variety of segmental levels, loading directions, load levels and testing methods among these studies, definite intradiscal pressure values for specific loading conditions, load levels and segmental levels potentially include high degrees of uncertainty, entailing a demand for cumulated data sets and metaanalyses of intradiscal pressure data. Previous studies have already provided data sets of combined in vivo (Wilke et al., 1999) and anthropometrical data (Wilke et al., 2001) as well as meta-analyses of in vivo and in silico data on intradiscal pressure values (Dreischarf $e t$ al., 2016). However, for the quantitative assessment of spinal loads and the validation of numerical models and experimental setups, clearly defined boundary conditions regarding loading types and segmental levels are required, emphasising the need for a metaanalysis of in vitro data from the literature. Therefore, 
the purpose of the present study was to collect and analyse all in vitro data on human intradiscal pressure measured under defined boundary conditions to provide a valid dataset for the estimation of loads and muscular forces on the spine as well as for the validation of numerical models and experimental setups in spine research.

\section{Methods}

\section{Study design}

The present study consisted of two main parts. In the first part, a systematic review of the literature was performed to collect all in vitro studies measuring the intradiscal pressure in human specimens under clearly defined boundary conditions. In the second part, a meta-analysis of the respective intradiscal pressure values was conducted with respect to loading direction and segmental level.

\section{Inclusion criteria for study selection}

In the first step, a systematic literature search on PubMed and Web of Science databases was performed using the keywords "intradiscal" and "intervertebral disc" combined with "pressure". Then, all in vitro studies presenting original intradiscal pressure data of human specimens were extracted (Fig. 1). Publications not written in the English language were excluded to ensure intelligibility of the presented methods and results. In the second step, the reference sections of all collected studies were carefully checked for potential further studies fulfilling the criteria of step 1. For final inclusion into the meta-analysis, the collected studies had to meet the following criteria (Fig. 1).

1. Intradiscal pressure was presented as an absolute value, either as a number or as a data point in a diagram.

2. Pressure measurement was performed in the centre of the nucleus pulposus.

3. Except for the sensor entry, the intervertebral disc was intact and no implant was inserted in the level of pressure measurement.

4. The segmental level of intradiscal pressure measurement and the sample size of isolated measurements were clearly stated in the article text or in the respective diagram.

5. Boundary conditions of the test setup were clearly defined. For the present analysis, solely force or moment-controlled loading scenarios were considered.

6. Loading, if performed, was applied in a single direction or in a single motion plane.

7. There was no long-term preconditioning of the specimen.

\section{Data acquisition}

In the third step (Fig. 1), the single intradiscal pressure data points of all selected studies were either acquired from values reported either in the article text or in tables or extracted from diagrams using an open-source software for image segmentation (Engauge Digitizer 12.1). This technique was already

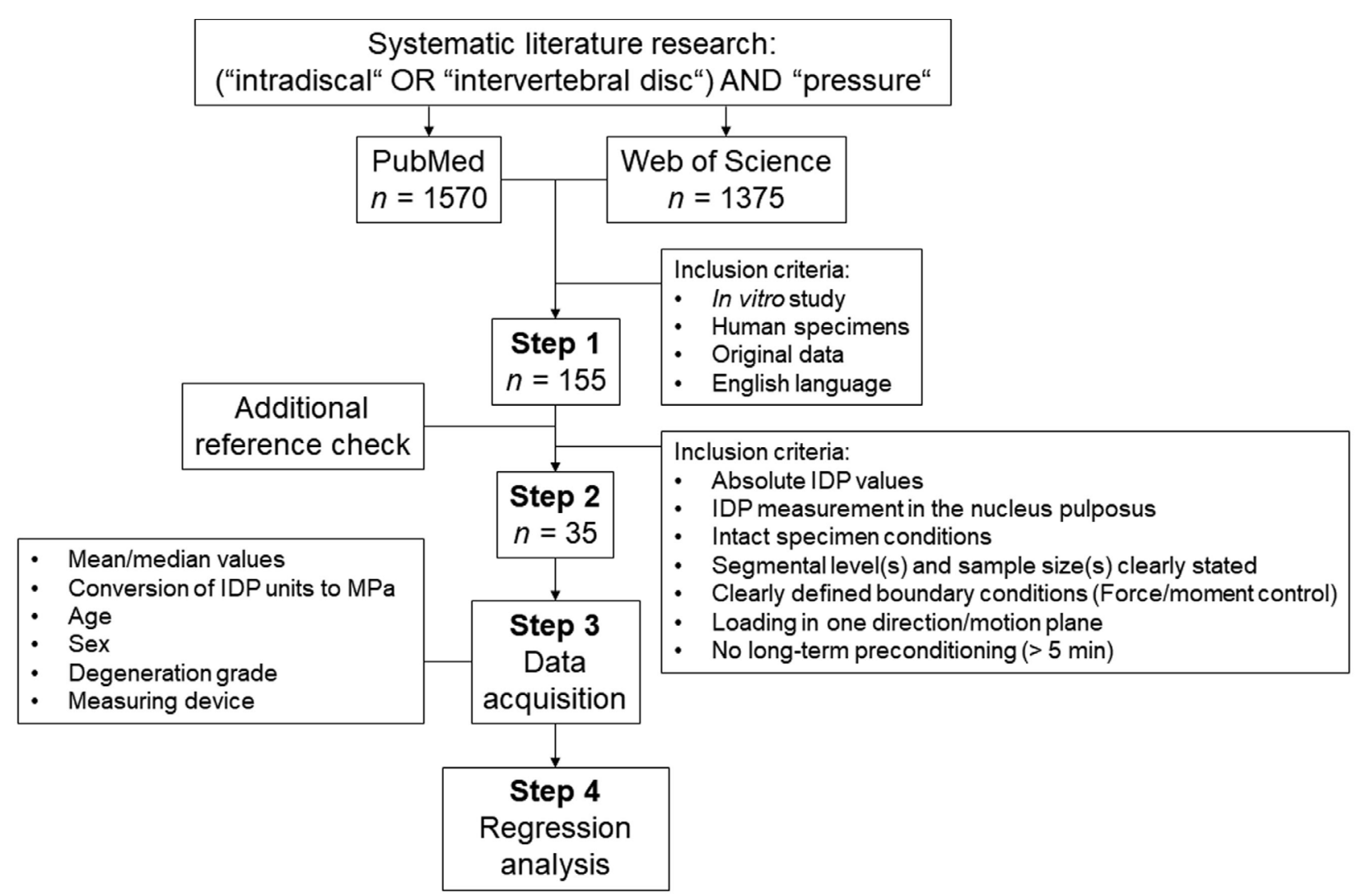

Fig. 1. Schematic illustration of the methodical approach from literature research to data analysis (IDP = intradiscal pressure). 
successfully used in a previous study analysing knee joint kinematics (Hacker et al., 2016). Then, the obtained data volume was post-processed using Excel 2016 (Microsoft Corporation). In case of multiple reported data points, all values of the respective study were acquired and used as single values for further analysis, while reported mean or median values were counted as single values. Intradiscal pressure values measured in lateral bending or axial rotation were averaged if bilateral values were reported. Pressure units other than $\mathrm{MPa}$ were converted to $\mathrm{MPa}$ to achieve quantitative comparability. Additionally, data on age, sex, intervertebral disc degeneration and the used measuring device were documented, if specified in the respective study.

\section{Statistical analysis}

To detect and evaluate potential relationships between intradiscal pressure values and segmental levels in the single loading directions, pressure values were normalised to the respective applied load or moment and regression analysis was performed using the statistics software SPSS 24 (IBM). First, curve-fitting algorithms including linear, quadratic, cubic, logarithmic and exponential regression models were used to gain the highest possible coefficient of determination for each loading direction. In the next step, an analysis of variance (ANOVA) was performed to verify the statistical significance of the respective regression fitting, while the significance level was set to 0.01 .

\section{Results}

\section{Selected publications}

Systematic literature search using the abovementioned inclusion criteria resulted in 35 publications (Table 1a-c), from which a total of 451 single intradiscal pressure values were extracted. Of these 35 studies, 10 reported measurements of intradiscal pressure in the cervical region (ID 1-10), 3 in the thoracic region (ID 11-13) and 22 in the lumbar region (ID 14-35). Specifications of age, sex and intervertebral disc degeneration of the tested specimens were not completely available among all studies but revealed overall large ranges regarding age (6-91 years) and disc degeneration (no-severe) as well as a larger proportion of male specimens (151) compared to female specimens (95). Applied axial forces varied from 50 to more than $2,000 \mathrm{~N}$, while applied moments ranged from 1 to $10 \mathrm{Nm}$. Of the 17 studies applying axial forces, 5 reported pure, unconstrained loading and 5 follower loading, while 6 studies did not explicitly state the axial loading type and 1 exhibited fully constrained axial loading. Of the 20 studies using moment application, 19 explicitly reported on pure moment loading. Overall, pressure sensors from 13 different companies were used, while sensors of Precision Measurements Co. (Raleigh, NC, USA) and MIPM GmbH (Mammendorf, Germany) were the most commonly reported devices, with 7 references each.

\section{Intrinsic intradiscal pressure}

Intradiscal pressure measured without external load application, also referred to as intrinsic pressure, revealed decreasing pressure values from upper cervical to mid and lower thoracic spinal regions, while increasing from the lower thoracic spine to the sacrum (Fig. 2). Regression analysis resulted in a statistically significant cubic curve $(p=0.003)$ with a low coefficient of determination $\left(r^{2}=0.266\right)$, showing a maximum of $0.21 \mathrm{MPa}$ at C2-C3 and a minimum of $0.05 \mathrm{MPa}$ at T9-T10.

\section{Intradiscal pressure under axial compression}

Axial compression exhibited a strong decrease in the intradiscal pressure from the upper cervical to the upper lumbar region, from where the pressure remained almost constant towards the sacrum (Fig. 3). The cubic regression curve exhibited a high coefficient of determination $\left(r^{2}=0.875\right)$ and statistically significant regression fitting $(p<0.001)$. The maximum of the cubic regression curve amounted to $4.35 \mathrm{MPa} / \mathrm{kN}$ at C2-C3, while the minimum was $0.72 \mathrm{MPa} / \mathrm{kN}$ at L1-L2.

\section{Intradiscal pressure in flexion}

Loading in flexion direction caused an exponential decrease in the intradiscal pressure from the upper cervical region to the sacrum (Fig. 4). The resulting regression curve showed a high coefficient of determination $\left(r^{2}=0.781\right)$ and was statistically significant $(p<0.001)$. The maximum of the exponential regression curve amounted to $0.28 \mathrm{MPa} / \mathrm{Nm}$ at $\mathrm{C} 2-\mathrm{C} 3$, while the minimum was $0.02 \mathrm{MPa} / \mathrm{Nm}$ at L5-S1.

\section{Intradiscal pressure in extension}

Pressure values during loading in extension direction tended to decrease from the upper cervical to the upper thoracic region and from the lower thoracic region to the sacrum, while being almost constant along the thoracic spine (Fig. 5). Regression analysis resulted in a statistically significant $(p<0.001)$ cubic curve, with a medium coefficient of determination $\left(r^{2}=0.574\right)$. The maximum of the cubic regression curve was $0.20 \mathrm{MPa} / \mathrm{Nm}$ at $\mathrm{C} 2-\mathrm{C} 3$ and the minimum $0.00 \mathrm{MPa} / \mathrm{Nm}$ at L5-S1, while the pressure remained almost constant between 0.5 and $0.6 \mathrm{MPa} / \mathrm{Nm}$ from T3-T4 to T12-L1.

\section{Intradiscal pressure in lateral bending}

In bilateral lateral bending, the intradiscal pressure tended to decrease from the upper cervical to the upper thoracic region and from the lower thoracic region to the sacrum (Fig. 6). In the thoracic spine, the intradiscal pressure remained almost constant but tended slightly to increase towards the thoracolumbar transition. A statistically significant $(p<0.001)$ cubic curve was obtained by regression analysis with a 


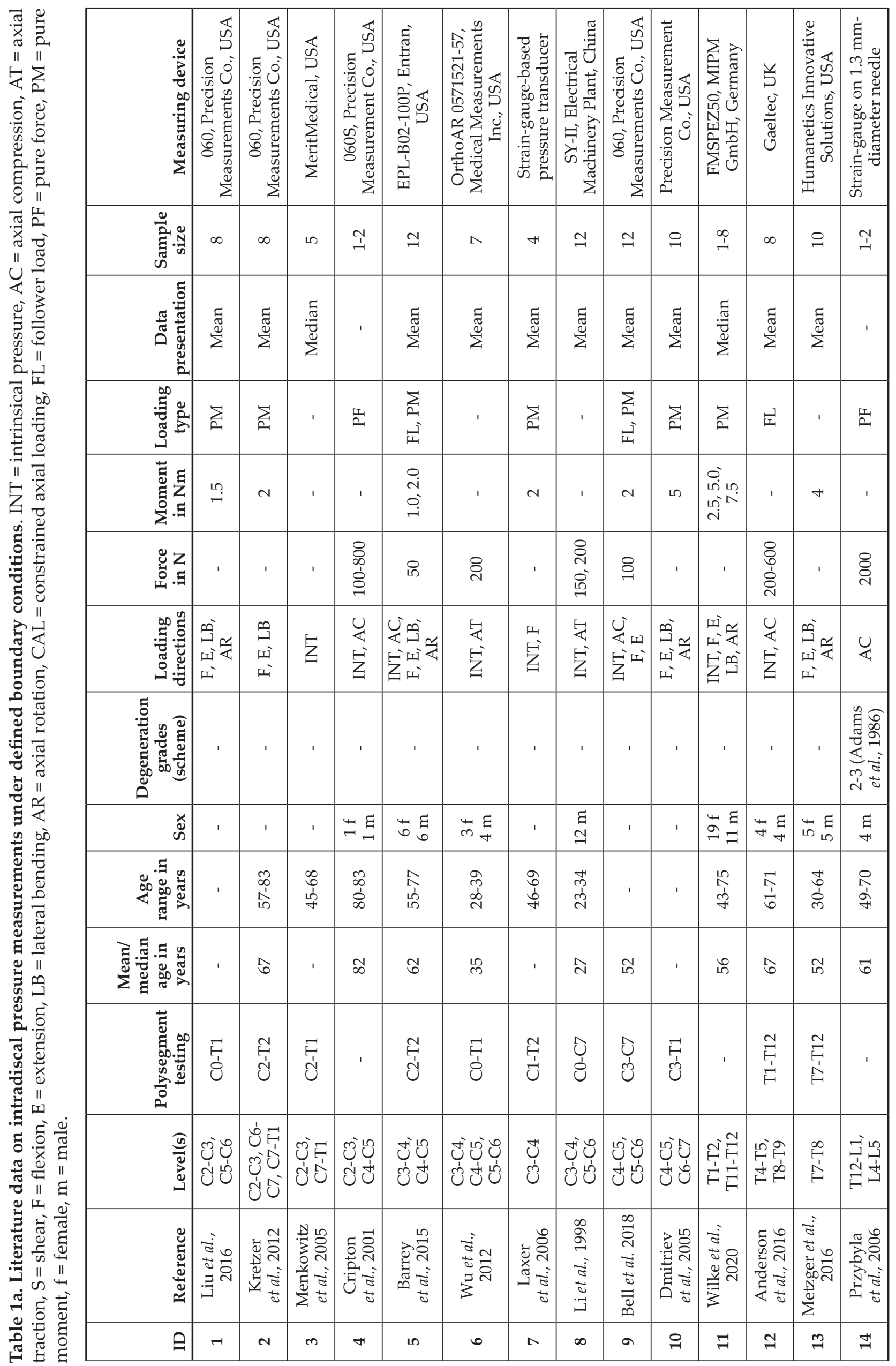




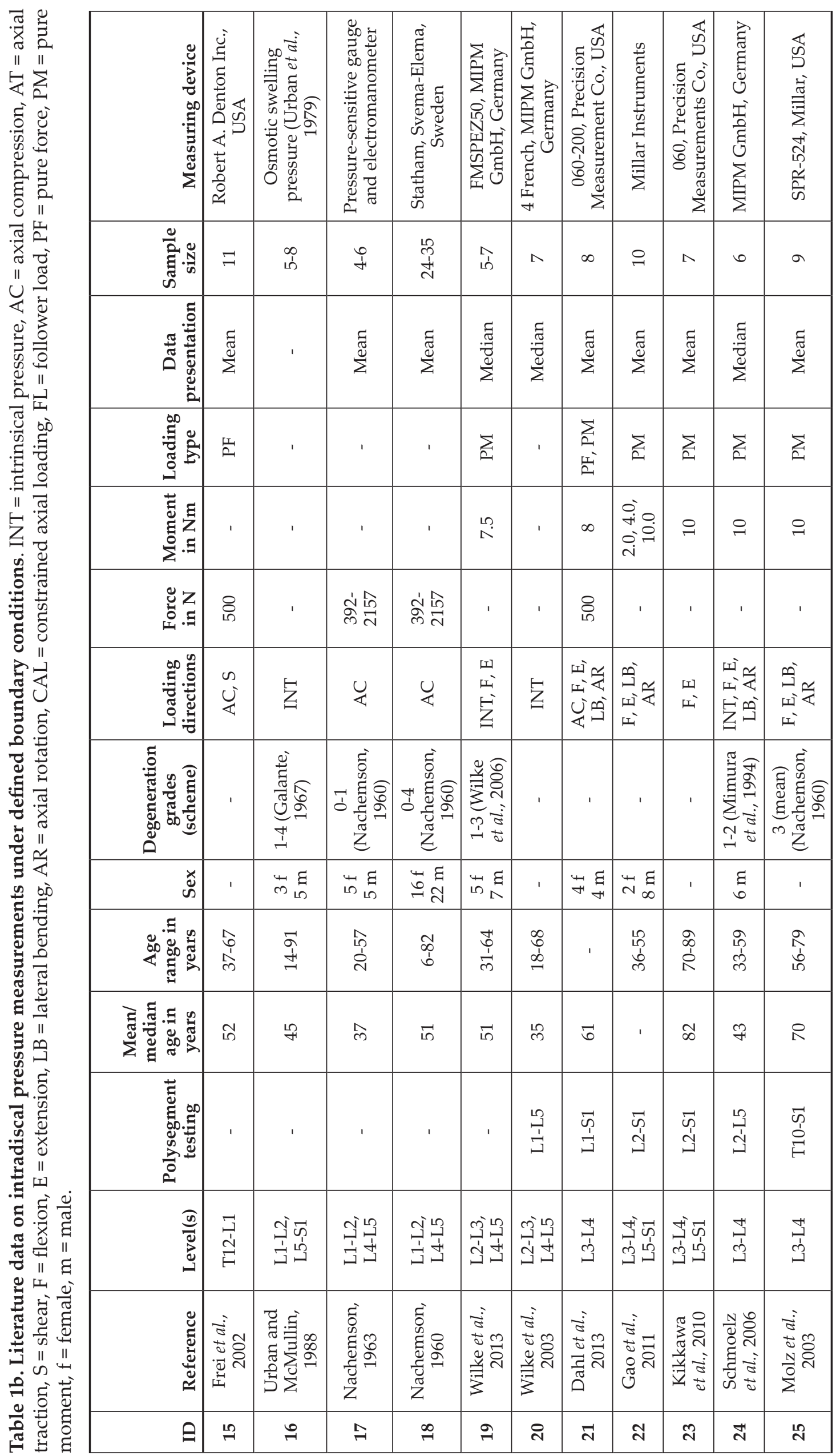




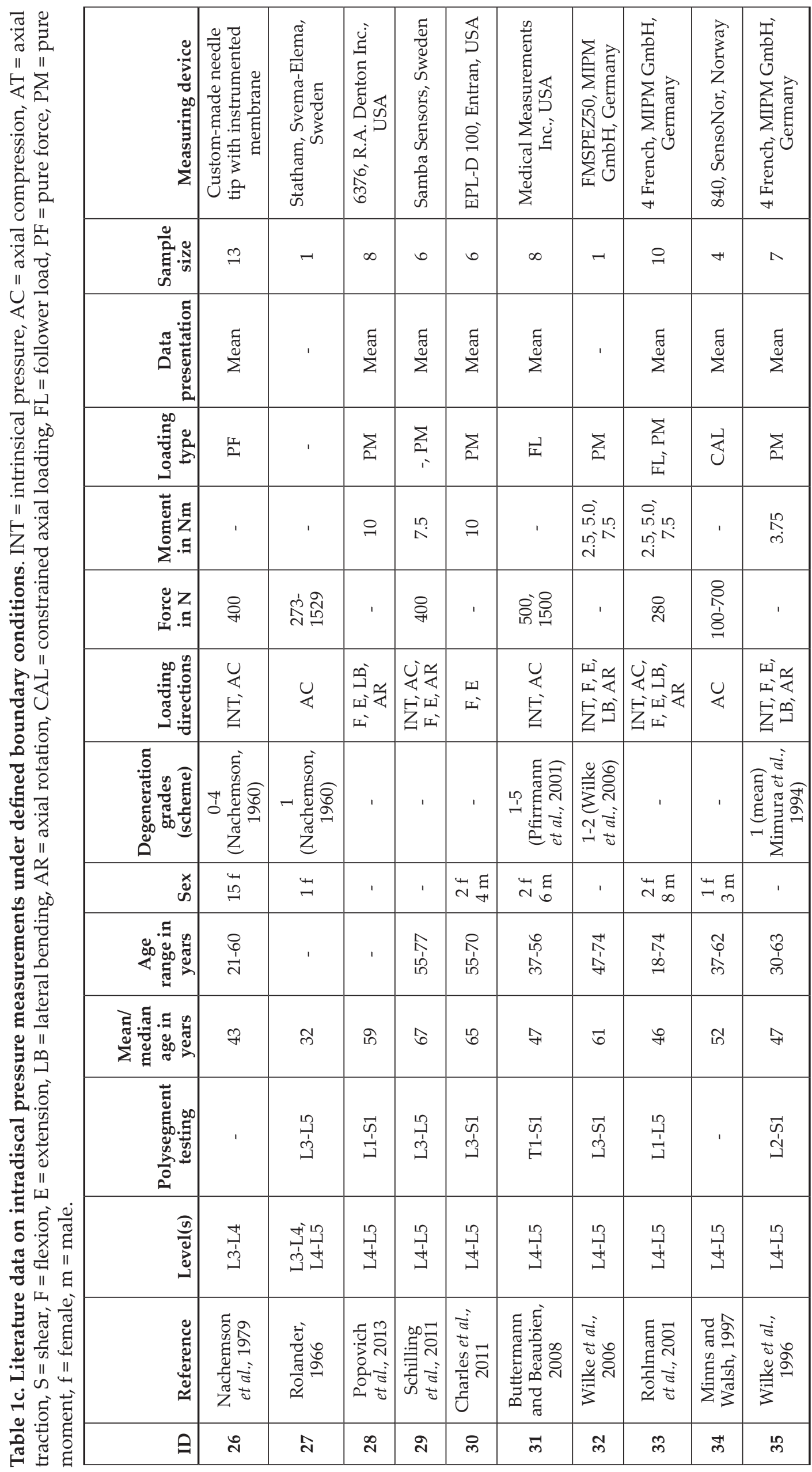


low coefficient of determination $\left(r^{2}=0.385\right)$, showing its global maximum of $0.15 \mathrm{MPa} / \mathrm{Nm}$ at $\mathrm{C} 2-\mathrm{C} 3$ and its global minimum of $0.00 \mathrm{MPa} / \mathrm{Nm}$ at L5-S1. Local minimum and maximum values were found at T3-T4 with $0.05 \mathrm{MPa} / \mathrm{Nm}$ and at T10-T11 with $0.06 \mathrm{MPa} / \mathrm{Nm}$.

\section{Intradiscal pressure in axial rotation}

Axial rotation generally caused low intradiscal pressure values, which tended to decrease exponentially from the upper cervical region to the sacrum (Fig. 7). Regression analysis led to a statistically significant $(p<0.001)$ exponential curve with a medium coefficient of determination $\left(r^{2}=0.570\right)$. The maximum of the exponential regression curve amounted to $0.12 \mathrm{MPa} / \mathrm{Nm}$ at $\mathrm{C} 2-$ $\mathrm{C} 3$, while the minimum was $0.02 \mathrm{MPa} / \mathrm{Nm}$ at L5-S1.

\section{Intradiscal pressure under axial traction and shear loading}

Only 2 studies were found reporting intradiscal pressure values measured under traction loading, both at the three cervical levels from C3-C4 to C5C6 (Li et al., 1998; Wu et al., 2012), exhibiting median values of $0.9,1.1$ and $1.2 \mathrm{MPa} / \mathrm{kN}$, maximum values of $1.47,1.53$ and $1.46 \mathrm{MPa} / \mathrm{kN}$ and minimum values of $0.54,0.44$ and $0.59 \mathrm{MPa} / \mathrm{kN}$, respectively. An

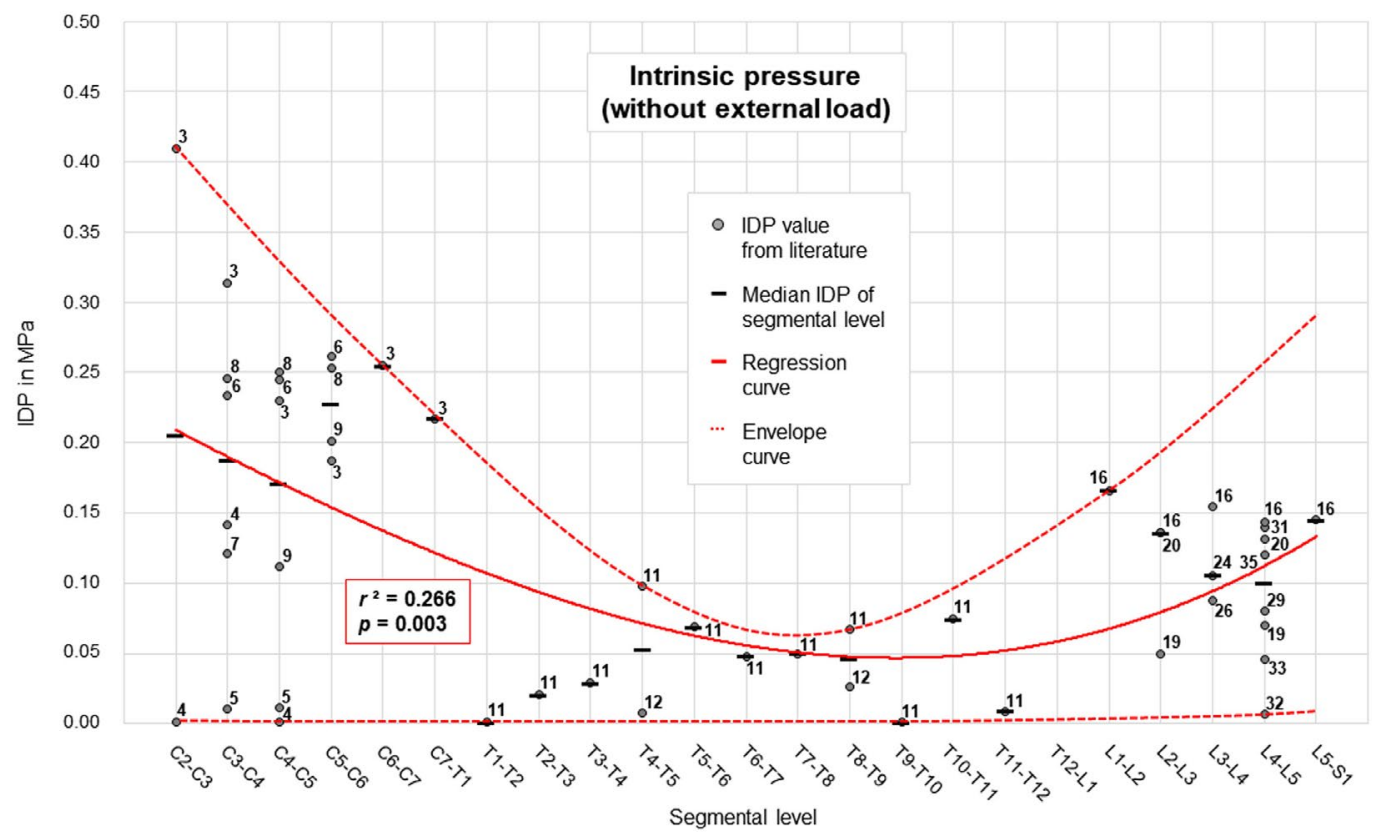

Fig. 2. Intradiscal pressure (IDP) values without external load application (intrinsic pressure) as a function of the segmental level. ID numbers next to the single data points specify the respective literature reference as defined in Table $1 \mathbf{a}-\mathbf{c}$.

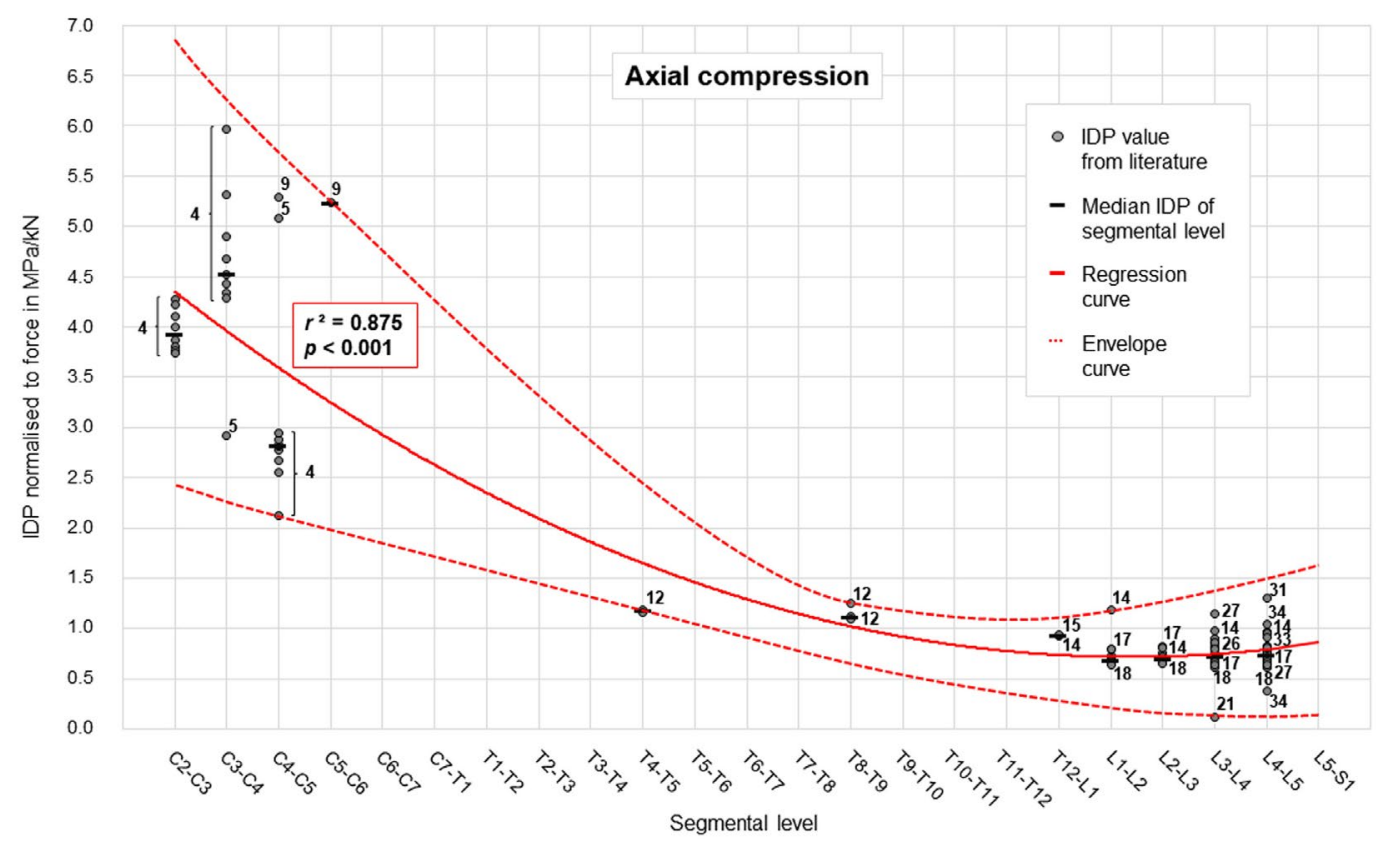

Fig. 3. Intradiscal pressure (IDP) values under axial compression as a function of the segmental level. ID numbers next to the single data points specify the respective literature reference as defined in Table 1a-c. 
investigation by Frei et al. (2002) represented the only study that investigated intradiscal pressures at T12-L1 under shear loading, reporting mean values of $0.11 \mathrm{MPa}$ in anterior shear, $0.13 \mathrm{MPa}$ in lateral shear and $0.23 \mathrm{MPa}$ in posterior shear under $500 \mathrm{~N}$ loading.

\section{Discussion}

The intradiscal pressure represents an important measure for the estimation of loads and muscle forces in the spine as well as for the validation of numerical models and experimental setups. Several studies have reported measurements of the intradiscal pressure in the human spine. However, experimental techniques, loading conditions and segmental levels varied considerably among these studies, potentially causing high degrees of uncertainty due to the lack of definite and valid intradiscal pressure values for specific loading directions and load levels. Therefore, the present meta-analysis aimed to collect and evaluate intradiscal pressure data from the literature

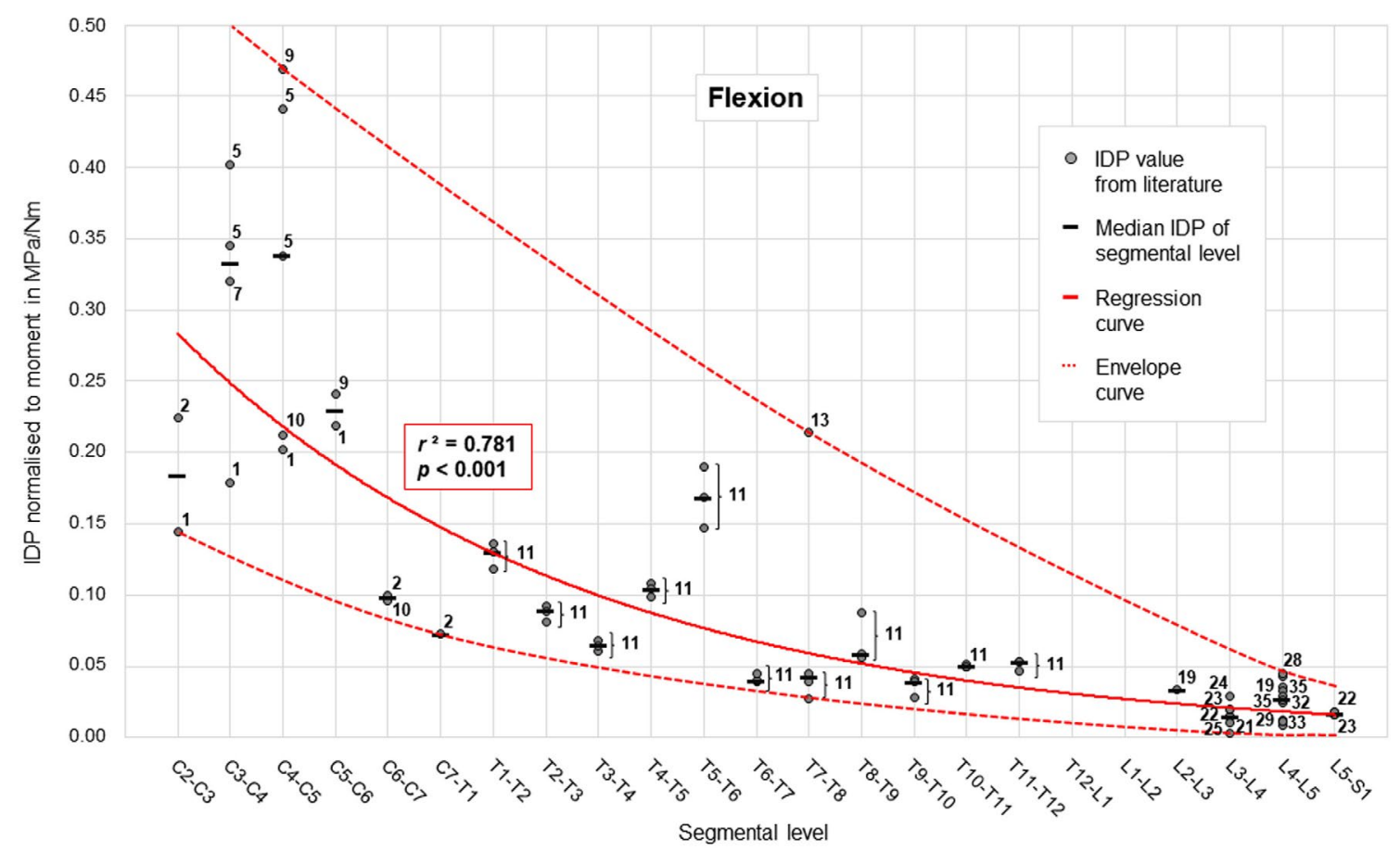

Fig. 4. Intradiscal pressure (IDP) values in flexion as a function of the segmental level. ID numbers next to the single data points specify the respective literature reference as defined in Table $1 \mathbf{a}-\mathbf{c}$.

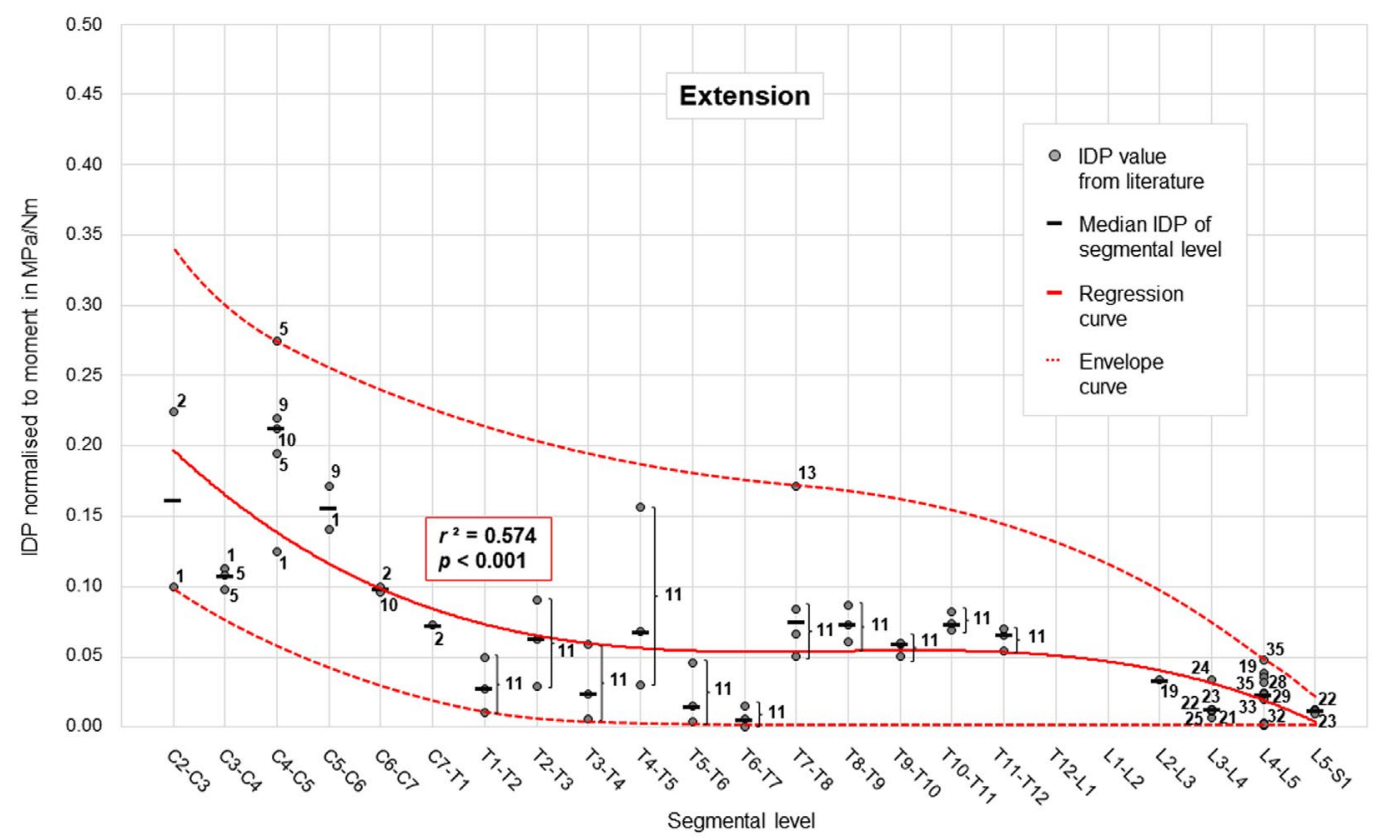

Fig. 5. Intradiscal pressure (IDP) values in extension as a function of the segmental level. ID numbers next to the single data points specify the respective literature reference as defined in Table 1a-c. 
regarding potential relationships between loading conditions and segmental levels in order to provide reliable guide values for load estimation and model validation.

Findings of the present meta-analysis exhibited the substantial influence of the loading condition on the relationship between intradiscal pressure and segmental level as well as on the variation range for each level in terms of the coefficient of determination. While obvious patterns and high coefficients of determination were found for axial compression and flexion loading, relatively low relationships were detected for intrinsic intradiscal pressure without external load application and for lateral bending loading. This might be caused by morphological factors, in particular the three-dimensional shape of the intervertebral disc as well as the specific ligamentous and articular properties of the functional spinal unit, which could have led to varying effects in the different loading directions. Moreover, the deformation behaviour of the intervertebral disc and the motion behaviour of the surrounding ligamentous and bony structures might have adapted to the most frequent loading types in daily life, which are particularly axial compression in upright position and flexion in forward bending. While axial compression exhibited the highest absolute pressure values in the evaluated studies, flexion showed the highest absolute values of all bending conditions, especially in the cervical region. This might indicate that the nucleus pulposus is mostly exposed to volumetric compression in axial compressive and flexion loading due to stronger interaction with the anulus fibrosus and the endplates. Extension, lateral bending, and axial rotation, in contrast, might be more affected by other morphological and material features, e.g. due to mobility restraint of the facet joints or stabilising effects of specific ligaments. Posterior elements, for instance, increase the intradiscal pressure under axial compression (Nachemson, 1960). Moreover, previous studies found low intradiscal pressure values and high value ranges (Wilke et al., 2020) or even inconsistent data (Schilling et al., 2011) in lateral bending loading, potentially explaining the low coefficient of determination in lateral bending loading in the present meta-analysis. Furthermore, the high variation range of the intrinsic pressure found in the present meta-analysis indicated that the quality of the nucleus pulposus in terms of water content, volume and fibrotic tissue ingrowth might have influenced the measurements of the hydrostatic intradiscal pressure, as previously described (Adams et al., 1986; Panjabi et al., 1988). However, for the estimation of loads and the validation of numerical models, the intrinsic intradiscal pressure may not be of major importance compared to conditions in which loading is applied. Nevertheless, these potential effects should be considered when validating experimental setups. Regional variations of intradiscal pressure in single loading conditions, on the other hand, may be explained by differences in the absolute and relative size of the nucleus pulposus along the spine. Pooni et al. (1986) showed that the cross-sectional area of the nucleus pulposus is gradually increasing from the upper cervical to the lower lumbar spine, potentially leading to decreasing intradiscal pressure in cranio-caudal direction as detected in the present meta-analysis, similar to the pressure differences between bike, car and truck tyres. Moreover, the average disc height, which was found to be the lowest in the mid-thoracic spine (Pooni et al., 1986), might have caused the low intrinsic pressure values found in this region in the present meta-analysis by directly determining the volume of the nucleus

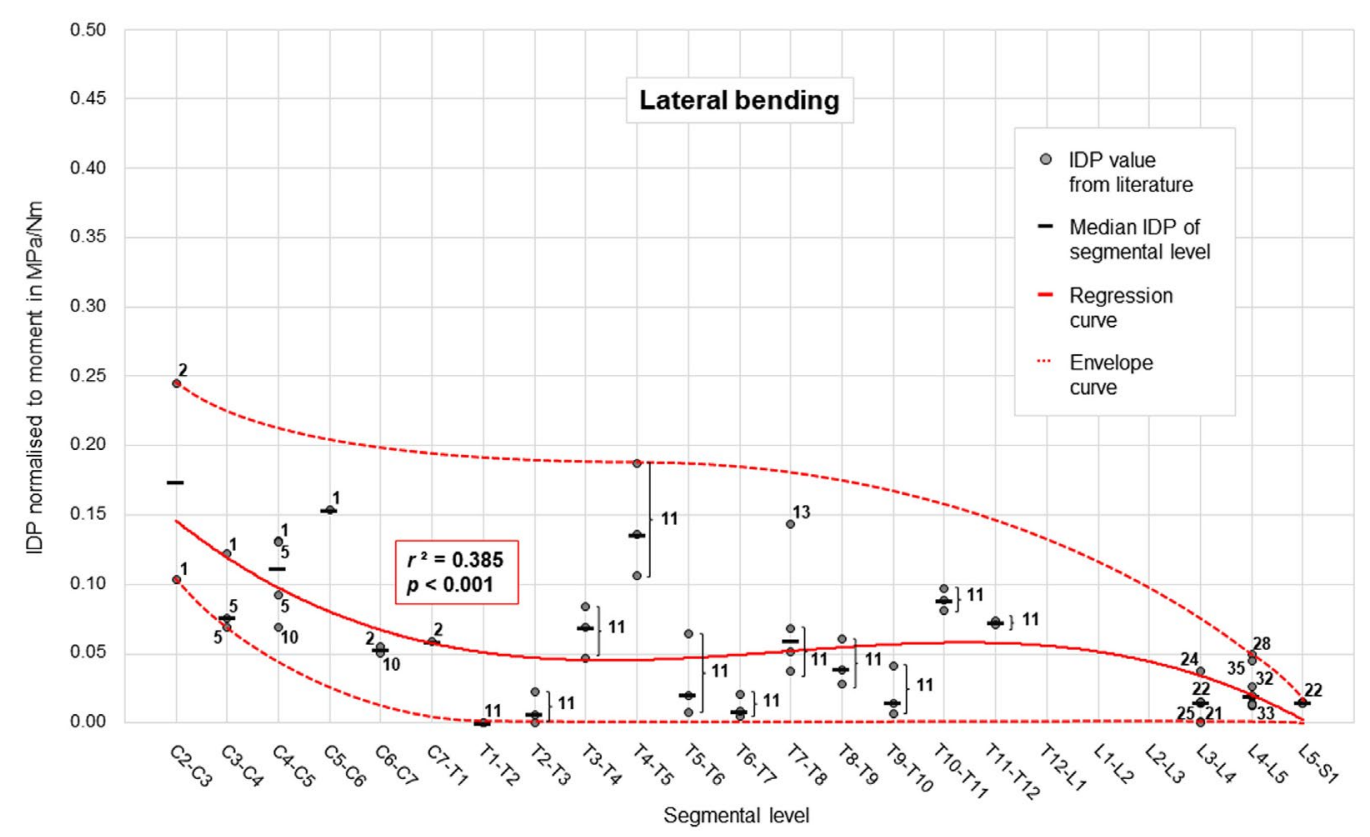

Fig. 6. Intradiscal pressure (IDP) values in lateral bending as a function of the segmental level. ID numbers next to the single data points specify the respective literature reference as defined in Table $1 \mathrm{a}-\mathrm{c}$. 
pulposus. As the nucleus pulposus size was not reported in most of the evaluated studies, the effect of these parameters on the intradiscal pressure should be further investigated in future studies. However, since the amount of loading increases also in craniocaudal direction in vivo, the physiological intradiscal pressure distribution might differ from the in vitro situation. Nevertheless, when comparing the findings of the present meta-analysis with the results of in vivo studies, similar trends regarding decreasing pressure values from the mid-thoracic spine to the lumbar spine were detected, especially with regard to the pressure values in upright standing position (Table 2 ). The results of these in vivo studies additionally indicate that the intradiscal pressure depends on the segmental level and the loading condition, while it could also be affected by intervertebral disc degeneration or the measurement technique, which should be further evaluated in future studies.

To ensure high data comparability, intradiscal pressure values were normalised to force in case of axial loading and to moment in case of bending loading due to the wide range of applied loads in the selected studies, which also inhibited the analysis of the effect of combined loading types on intradiscal pressure. However, normalisation requires quasilinear relationship between the applied load and the resulting intradiscal pressure. Regarding axial compression, several studies showed an almost perfect linear relationship between load and pressure (Anderson et al., 2016; Brinckmann and Grootenboer, 1991; Buttermann and Beaubien 2008; Cripton et al., 2001; Nachemson, 1960; Nachemson, 1963; Rolander, 1966). One study reported a non-linear relationship under high compression loads, which might have been caused by the constrained loading conditions described in the study (Minns and Walsh, 1997), which, however, did not essentially affect the normalised values. In case of moment application, the findings of most previous studies indicate a quasi-linear relationship between moment and intradiscal pressure in the loading phase (Barrey et al., 2015; Charles et al., 2011; Rohlmann et al., 2001; Schmoelz et al., 2006; Wilke et al., 2020; Wilke et al., 1996; Wilke et al., 2013; Wilke et al., 2006). However, some other studies suggest non-linear behaviour in the initial phase of moment loading (Molz et al., 2003) or by applying high moments (Nachemson et al., 1979). Therefore, the results of the present meta-analysis might be affected by a potential nonlinear behaviour between intradiscal pressure and the applied moment, which should be considered when using the data for model validation purposes. However, due to the high variation regarding applied forces and moments in the selected studies, a quantitative comparison of the data would not have been feasible without normalisation. For the validation of numerical or experimental models, in any case, loading should not exceed the maximum limits reported in the selected studies for the different spinal regions (Table $1 \mathrm{a}-\mathrm{c}$ ).

It was not possible to evaluate the effects of age, sex and intervertebral disc degeneration on the intradiscal pressure due to the large variability of the reported data in the selected publications. However, previous studies found that increasing age and male gender cause more likely intervertebral disc degeneration (Adams et al., 1996; Goh et al., 2000), which might have affected the results of the present meta-analysis due to the large proportion of elderly and male donors (Table 1a-c). Furthermore, these studies indicate that disc degeneration is affected

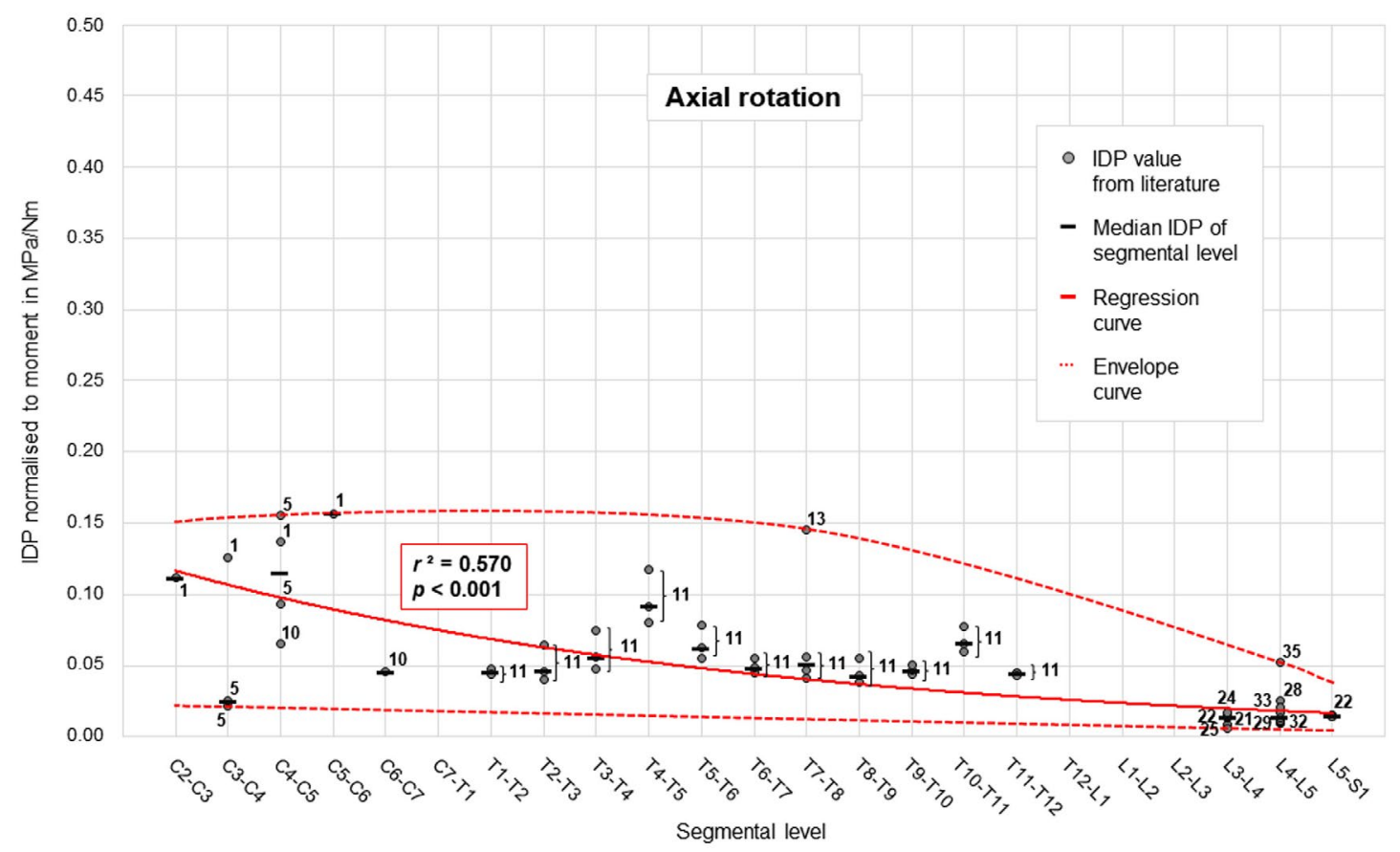

Fig. 7. Intradiscal pressure (IDP) values in axial rotation as a function of the segmental level. ID numbers next to the single data points specify the respective literature reference as defined in Table 1a-c. 
Table 2. Literature data on in vivo intradiscal pressure (IDP) measurements.

\begin{tabular}{|c|c|c|c|c|c|c|c|c|c|}
\hline & & $\begin{array}{c}\text { Mean/ } \\
\text { median } \\
\text { age in } \\
\text { Rears }\end{array}$ & $\begin{array}{c}\text { Age } \\
\text { range in } \\
\text { years }\end{array}$ & Sex & $\begin{array}{c}\text { Lying prone } \\
\text { (IDP in MPa, } \\
\text { mean } \pm \text { SD) }\end{array}$ & $\begin{array}{c}\text { Sitting upright } \\
\text { (IDP in MPa, } \\
\text { mean } \pm \text { SD) }\end{array}$ & $\begin{array}{c}\text { Standing upright } \\
\text { (IDP in MPa, } \\
\text { mean } \pm \text { SD) }\end{array}$ & $\begin{array}{c}\text { Sample } \\
\text { size }\end{array}$ & Measuring device \\
\hline $\begin{array}{c}\text { Polga } \text { et al., } \\
\text { 2004 }\end{array}$ & $\begin{array}{c}\text { T6-T7, } \\
\text { T7-T8 }\end{array}$ & 28 & $19-47$ & $\begin{array}{c}2 \mathrm{f} \\
4 \mathrm{~m}\end{array}$ & $0.29 \pm 0.04$ & $0.99 \pm 0.06$ & $1.01 \pm 0.06$ & 6 & $\begin{array}{c}\text { Tokai Rika Co., } \\
\text { Japan }\end{array}$ \\
\hline $\begin{array}{c}\text { Polga } \text { et al., } \\
\text { 2004 }\end{array}$ & $\begin{array}{c}\text { T9-T10, } \\
\text { T10-T11 }\end{array}$ & 28 & $19-47$ & $\begin{array}{c}2 \mathrm{f} \\
4 \mathrm{~m}\end{array}$ & $0.20 \pm 0.03$ & $0.88 \pm 0.04$ & $0.86 \pm 0.06$ & 6 & $\begin{array}{c}\text { Tokai Rika Co., } \\
\text { Japan }\end{array}$ \\
\hline $\begin{array}{c}\text { Nachemson } \\
\text { and Elfström, } \\
1970\end{array}$ & L3-L4 & 28 & $14-60$ & $\begin{array}{c}6 \mathrm{f} \\
3 \mathrm{~m}\end{array}$ & $0.38 \pm 0.03$ & $1.00 \pm 0.10$ & $0.71 \pm 0.12$ & $5-9$ & $\begin{array}{c}\text { Semiconductor } \\
\text { strain gauges in } \\
\text { rigid resin in an } \\
\text { elastic tube }\end{array}$ \\
\hline $\begin{array}{c}\text { Sato } \text { et al., } \\
\text { 1999 }\end{array}$ & L4-L5 & 45 & $19-74$ & $\begin{array}{c}10 \mathrm{f} \\
18 \mathrm{~m}\end{array}$ & $0.09 \pm 0.03$ & $0.54 \pm 0.18$ & $0.62 \pm 0.16$ & 28 & $\begin{array}{c}\text { Tokai Rika Co., } \\
\text { Japan }\end{array}$ \\
\hline $\begin{array}{c}\text { Wilke } \text { et al., } \\
\text { 1999 }\end{array}$ & L4-L5 & 45 & - & $1 \mathrm{~m}$ & 0.11 & 0.55 & 0.5 & 1 & $\begin{array}{c}5 \text { French, MIPM } \\
\text { GmbH, Germany }\end{array}$ \\
\hline
\end{tabular}

by the disc level, potentially leading to even lower intradiscal pressure in the lumbar spine, which might have also influenced the outcome of the present meta-analysis. Until now, the effect of disc degeneration on intradiscal pressure has been mainly investigated for axial compression loading, overall showing decreasing pressure values for increasing degeneration grades (Adams et al., 1996; Stefanakis et al., 2014; Zehra et al., 2019). However, the influence of bending loading has been poorly investigated, which should be considered in future studies. A potential effect of the transducer type on intradiscal pressure values was not detected in the present study, although it was expected that rigid sensors may provide divergent data compared to flexible sensors. However, studies using rigid pressure transducers (Laxer et al., 2006; Minns and Walsh, 1997; Nachemson, 1960; Nachemson, 1963; Nachemson, et al., 1979; Rolander, 1966) exhibited comparable pressure values in the present meta-analysis but were predominantly used for axial compression testing, where the intervertebral disc is not unilaterally deformed. Therefore, flexible pressure transducers should be favoured when measuring intradiscal pressure under multi-planar bending loading. Other measurement technologies, such as stress profilometry or osmometry, were also included in the review process and represent useful and valid methods for the determination of the intradiscal pressure. However, none of the studies using one of these methods met all the predefined inclusion criteria. Studies reporting long-term preconditioning of their specimens were also excluded from further analysis for two main reasons. First, most in vitro studies investigating intradiscal pressure did not use long-term preconditioning, while inclusion of studies using this method could have potentially increased the data variability. Moreover, in silico studies that might use the data of this meta-analysis for model validation usually do not simulate longterm preconditioning, potentially causing limitations to the validation process. Nevertheless, long-term preconditioning represents a valuable method to simulate the human intervertebral disc fluid loss and, therefore, is more physiological when compared to its absence. While the intradiscal pressure values presumably would decrease after long-term preconditioning, future in vitro and in silico studies should take this constraint into account when using the data of the present meta-analysis.

The present meta-analysis had some limitations regarding the statistical evaluation of the data. Mean and median values reported in the selected studies were included as single data points in the analysis despite their underlying sample size. Rating of these values depending on the sample size would have been possible but was refrained from to not distort the outcome variation ranges. Furthermore, analysing the data using regression models impeded the inclusion of standard deviations from the selected studies. The method of regression analysis itself is also limited due to potential smoothening of effects in transition areas, such as the cervicothoracic and the thoracolumbar region. Moreover, the method of curve fitting does not completely ensure a consistent data evaluation among the single loading conditions. However, it represented the best possible approach to take into account the different data distribution characteristics, whereas using the same regression model was not feasible without obtaining an overall lower regression quality. Another limitation was that the coefficient of determination did not indicate whether an adequate number of data points was included to receive solid results. Therefore, for the validation of numerical models or experimental setups, the regression curves presented in the present study represent guide values, which have to be used in combination with their variation ranges, which, however, might be affected by potential outliers. A removal of these potential outliers was considered but not performed, since the respective publications did not raise the suspicion of incorrect use of methods. Moreover, the completeness of data should be ensured to allow the reader to have a comprehensive view of the literature, while a certain degree of data variability was seen, as expected with regard to the nature of experimental testing. Furthermore, considering the scarce, scattered and potentially unphysiologically 
determined data found in the literature, the results of the present meta-analysis should be used with caution. Nevertheless, the present meta-analysis provided a large and valid data set for validation purposes by combining these highly variable data. Moreover, the presented data may help to understand the multiplanar load distribution along the spine in combination with the physiologically acting loads on the intervertebral discs. These should be determined in more detail in future studies, preferably by using long-term preconditioning of the specimens and highly reproducible measurement techniques, as well as by investigating the intradiscal pressure of all spinal levels under different loading conditions.

\section{Acknowledgments}

The present study was supported by the German Research Foundation (DFG, WI1352/14-3 and WI1352/20-2). The funding agency had no influence on study design, data collection, data analysis and interpretation, writing the manuscript or the decision to submit the article for publication.

\section{References}

Adams MA, Dolan P, Hutton WC (1986) The stages of disc degeneration as revealed by discograms. J Bone Joint Surg Br 68: 36-41.

Adams MA, McNally DS, Dolan P (1996) 'Stress' distributions inside intervertebral discs. The effects of age and degeneration. J Bone Joint Surg Br 78: $965-$ 972.

Anderson DE, Mannen EM, Sis HL, Wong BM, Cadel ES, Friis EA, Bouxsein ML (2016) Effects of follower load and rib cage on intervertebral disc pressure and sagittal plane curvature in static tests of cadaveric thoracic spines. J Biomech 49: 1078-1084.

Barrey C, Rousseau MA, Persohn S, Campana S, Perrin G, Skalli W (2015) Relevance of using a compressive preload in the cervical spine: an experimental and numerical simulating investigation. Eur J Orthop Surg Traumatol 25: 155-165.

Brinckmann P, Grootenboer H (1991) Change of disc height, radial disc bulge, and intradiscal pressure from discectomy. An in vitro investigation on human lumbar discs. Spine (Phila Pa 1976) 16: 641-646.

Buttermann GR, Beaubien BP (2008) In vitro disc pressure profiles below scoliosis fusion constructs. Spine (Phila Pa 1976) 33: 2134-2142.

Charles YP, Persohn S, Steib JP, Mazel C, Skalli W (2011) Influence of an auxiliary facet system on lumbar spine biomechanics. Spine (Phila Pa 1976) 36: 690-699.

Cripton PA, Dumas GA, Nolte LP (2001) A minimally disruptive technique for measuring intervertebral disc pressure in vitro: application to the cervical spine. J Biomech 34: 545-549.
Dreischarf M, Shirazi-Adl A, Arjmand N, Rohlmann A, Schmidt H (2016) Estimation of loads on human lumbar spine: a review of in vivo and computational model studies. J Biomech 49: 833-845.

Frei H, Oxland TR, Nolte LP (2002) Thoracolumbar spine mechanics contrasted under compression and shear loading. J Orthop Res 20: 1333-1338.

Goh S, Tan C, Price RI, Edmondston SJ, Song S, Davis S, Singer KP (2000) Influence of age and gender on thoracic vertebral body shape and disc degeneration: an MR investigation of 169 cases. J Anat 197: 647-657.

Hacker SP, Ignatius A, Durselen L (2016) The influence of the test setup on knee joint kinematics - a meta-analysis of tibial rotation. J Biomech 49: 29822988.

Laxer EB, Darden BV, Murrey DB, Milam RA, Rhyne AL, Claytor B, Nussman DS, Powers TW, Davies MA, Bryant SC, Larsen SP, Bhatt M, Brodziak J, Polic J (2006) Adjacent segment disc pressures following two-level cervical disc replacement versus simulated anterior cervical fusion. Stud Health Technol Inform 123: 488-492.

Li YK, Zhu QA, Zhong SZ (1998) The effect of cervical traction combined with rotatory manipulation on cervical nucleus pulposus pressures. J Manipulative Physiol Ther 21: 97-100.

Minns RJ, Walsh WK (1997) Preliminary design and experimental studies of a novel soft implant for correcting sagittal plane instability in the lumbar spine. Spine (Phila Pa 1976) 22: 1819-1825.

Molz FJ, Partin JI, Kirkpatrick JS (2003) The acute effects of posterior fusion instrumentation on kinematics and intradiscal pressure of the human lumbar spine. J Spinal Disord Tech 16: 171-179.

Nachemson A (1959) Measurement of intradiscal pressure. Acta Orthop Scand 28: 269-289.

Nachemson A (1960) Lumbar intradiscal pressure. Experimental studies on post-mortem material. Acta Orthop Scand Suppl 43: 1-104.

Nachemson A (1963) the influence of spinal movements on the lumbar intradiscal pressure and on the tensil stresses in the annulus fibrosus. Acta Orthop Scand 33: 183-207.

Nachemson A, Elfström G (1970) Intravital dynamic pressure measurements in lumbar discs. A study of common movements, maneuvers and exercises. Scand J Rehabil Med Suppl 1: 1-40.

Nachemson AL, Schultz AB, Berkson MH (1979) Mechanical properties of human lumbar spine motion segments. Influence of age, sex, disc level, and degeneration. Spine (Phila Pa 1976) 4: 1-8.

Panjabi M, Brown M, LindahlS, Irstam L, Hermens M (1988) Intrinsic disc pressure as a measure of integrity of the lumbar spine. Spine (Phila Pa 1976) 13: 913-917.

Polga DJ, Beaubien BP, Kallemeier PM, Schellhas KP, Lew WD, Buttermann GR, Wood KB (2004). Measurement of in vivo intradiscal pressure in healthy thoracic intervertebral discs. Spine (Phila Pa 1976) 29: 1320-1324. 
Pooni JS, Hukins DW, Harris PF, Hilton RC, Davies KE (1986) Comparison of the structure of human intervertebral discs in the cervical, thoracic and lumbar regions of the spine. Surg Radiol Anat 8: 175-182.

Rohlmann A, Neller S, Claes L, Bergmann G, Wilke HJ (2001) Influence of a follower load on intradiscal pressure and intersegmental rotation of the lumbar spine. Spine (Phila Pa 1976) 26: E557-E561.

Rolander SD (1966) Motion of the lumbar spine with special reference to the stabilizing effect of posterior fusion. An experimental study on autopsy specimens. Acta Orthop Scand Suppl 90: 1-144.

Sato K, Kikuchi S, Yonezawa T (1999). In vivo intradiscal pressure measurement in healthy individuals and in patients with ongoing back problems. Spine (Phila Pa 1976) 24: 2468-2474.

Schilling C, Kruger S, Grupp TM, Duda GN, Blomer W, Rohlmann A (2011) The effect of design parameters of dynamic pedicle screw systems on kinematics and load bearing: an in vitro study. Eur Spine J 20: 297-307.

Schmoelz W, Huber JF, Nydegger T, Claes L, Wilke HJ (2006) Influence of a dynamic stabilisation system on load bearing of a bridged disc: an in vitro study of intradiscal pressure. Eur Spine J 15: 12761285.

Stefanakis M, Luo J, Pollintine P, Dolan P, Adams MA (2014) ISSLS Prize winner: Mechanical influences in progressive intervertebral disc degeneration. Spine (Phila Pa 1976) 39: 1365-1372.

Wilke HJ, Herkommer A, Werner K, Liebsch C (2020) In vitro analysis of the intradiscal pressure of the thoracic spine. Front Bioeng Biotechnol 8: 614. DOI: $10.3389 /$ fbioe.2020.00614.

Wilke HJ, Neef P, Caimi M, Hoogland T, Claes LE (1999) New in vivo measurements of pressures in the intervertebral disc in daily life. Spine (Phila Pa 1976) 24: 755-762.

Wilke HJ, Neef P, Hinz B, Seidel H, Claes L (2001) Intradiscal pressure together with anthropometric data - a data set for the validation of models. Clin Biomech 16: S111-S126.
Wilke HJ, Ressel L, Heuer F, Graf N, Rath S (2013) Can prevention of a reherniation be investigated? Establishment of a herniation model and experiments with an anular closure device. Spine (Phila Pa 1976) 38: E587-E593.

Wilke HJ, Schmidt H, Werner K, Schmölz W, Drumm J (2006) Biomechanical evaluation of a new total posterior-element replacement system. Spine (Phila Pa 1976) 31: 2790-2796.

Wilke HJ, Wolf S, Claes LE, Arand M, Wiesend A (1996) Influence of varying muscle forces on lumbar intradiscal pressure: an in vitro study. J Biomech 29: 549-555.

Wu LP, Huang YQ, Zhou WH, Manas D, Zhao WD, Chen JZ, Yin QS, Wang LH (2012) Influence of cervical spine position, turning time, and cervical segment on cadaver intradiscal pressure during cervical spinal manipulative therapy. J Manipulative Physiol Ther 35: 428-436.

Zehra U, Noel-Barker N, Marshall J, Adams MA, Dolan P (2019) Associations between intervertebral disc degeneration grading schemes and measures of disc function. J Orthop Res 37: 1946-1955.

\section{Discussion with Reviewer}

Theo Smit: Intradiscal pressure is a major marker of disc degeneration, which in turn affects intradiscal pressure. How can we quantify the effect of degeneration on the data points and, therefore, of the mathematical fitting curves?

Authors: Since the reported data are based on studies that evaluated intradiscal pressure but not disc degeneration, the effect of degeneration on the intradiscal pressure data was unfortunately not quantifiable. However, it can be assumed that all data points below the regression curve originate from discs that were more likely affected by degeneration. Future studies should focus on this issue.

Editor's note: The Scientific Editor responsible for this paper was Mauro Alini. 